\title{
Zonificación Hidrogeológica para el manejo de los recursos hídricos de la subcuenca Río Gil González, Rivas
}

\author{
Maynor Ruiz Álvarez ${ }^{1}$ Yelba Flores Meza ${ }^{2}$ \\ Centro para la Investigación en Recursos Acuáticos de Nicaragua \\ 1 Estudiante de III Ciclo de Maestría Regional en Ciencias del Agua. MCA-CIRA-UNAN. \\ ruizalva05@yahoo.com. \\ 2 Centro para la Investigación de los Recursos Acuáticos de Nicaragua. CIRA-UNAN yelba.flores@cira- \\ unan.edu.ni,
}

\section{RESUMEN}

Se ha realizado la zonificación hidrogeológica para el manejo de los recursos hídricos de la subcuenca Rio Gil González, utilizando la superposición de evaluaciones: geológica, hidrológica e hidrogeológica. Se utilizaron los criterios geológicos, hidrogeológicos, tipo de suelos para definir cada una de las zonas, basadas en similaridad de propiedades hidráulicas del medio geológico. La subcuenca del Rio Gil González se localiza en el flanco Oeste del Lago Cocibolca, pertenece a la cuenca de los grandes Lagos Nicaragüenses y es compartida por los municipios de Belén, Potosí y Buenos Aires, con un área total de $68.43 \mathrm{Km}^{2}$. Geomorfológicamente se establecieron tres tipos de relieve montañoso, ondulado o colinas y valles, todos dominados por los tipos de rocas La geología está dominada por sedimentos cretácicos de la Formación Rivas y Sedimentos Cuaternarios, acumulados por erosión y deposición aluvial. Los tipos de suelos dominantes son suelos Alfisoles, Vertisoles y Entisoles dominantemente suelos arcilloso con una permeabilidad limitada. Se establecieron cuatro zonas hidrogeológicas; acuíferos aluviales, acuíferos fracturados, acuíferos intramontanos y esteros y humedales.

Palabra Clave: Geología, Suelo, Hidrogeología, Zonificación Hidrogeológica,

\section{INTRODUCCIÓN}

La subcuenca Rio Gil González con $68.43 \mathrm{~km}^{2}$ de superficie, pertenece a la cuenca No. 69 Río San Juan. Desde su parte más alta en la divisoria de aguas que drenan hacia al océano Pacifico hasta la parte más baja cerca del Lago de Nicaragua, se encuentra compartido por los municipios de Belén, Potosí y Buenos Aires, lo que le confiere un carácter intermunicipal. El objetivo principal de este estudio es la zonificación hidrogeológica como herramienta para el plan de manejo de los recursos hídricos, contribuyendo con datos técnicos-científicos de la disponibilidad y aprovechamiento sostenible de los recursos hídricos. Las actividades agropecuarias han provocado la deforestación. El cambio ambiental, según los pobladores, ha provocado la desaparición de algunos manantiales, profundización del nivel del agua y baja en los caudales del río, hasta desaparecer en época de estiaje.

En el año 1995 Krasny y Hetch (INETER), realizaron la "Caracterización Hidrogeológica e Hidrogeoquímica de la Región Pacifica". Este trabajo incluye el acuífero de Nandaime de forma general, sin la subdivisión a acuíferos locales. El CIRA-UNAN (2006), determinó que el balance presentaba un déficit por la pérdida de capacidad de retención del suelo, especialmente en la parte 
alta y media. Esto motivó a la alcaldía de Belén, como parte del Plan de Desarrollo Municipal, a través del proyecto MASRENACE, ejecutado con el apoyo de la cooperación alemana a través de DED y GTZ, MARENA, INTA y CASUR, a realizar una zonificación en la parte alta de la subcuenca. Se crearon zonas de conservación, zonas de uso agropecuario y se reforestaron 800 hectáreas. Actualmente se desarrolla dentro de la subcuenca un proyecto de PSA, financiado por la UE, CASUR, GIZ y las Alcaldías de los Municipios que la conforman. Este, fue echado a andar sin un estudio a detalle de la viabilidad, ya que los estudios anteriores eran muy generales.

Se presenta ahora una zonificación a detalle de la hidrogeología de la subcuenca. El fin es diferenciar zonas de productividad. De esta manera las actividades de recuperación y conservación podrán enfocarse en las zonas de mayor dinámica hídrica.

\section{MATERIAL Y MÉTODOS}

Caracterización Geológica: A partir de información existente se determinaron los tipos de rocas y estructuras. Se definieron las unidades geomorfológicas. Luego se realizó el reconocimiento y verificación en el campo de la información anterior y generación de información nueva, relevante para el estudio.

Hidrología e Hidrogeología: Se realizó la caracterización física a detalle de de la subcuenca, para determinar el comportamiento frente a la precipitación. Se realizaron mediciones mensuales del caudal de los principales tributarios y el río principal. Se instalaron dispositivos para determinar la relación río-acuífero. La caracterización hidrogeológica se basó en la determinación del comportamiento de manantiales y niveles de pozo en el mismo período de medición de caudales. El análisis de la dinámica se comparó con métodos empíricos que utilizan la precipitación y temperatura como parámetros principales.

Zonificación Hidrogeológica: Determinado el comportamiento superficial y subterráneo de los recursos hídricos, se definieron zonas con similares características hidráulicas. Esta zonificación es la herramienta que los tomadores de decisiones podrán utilizar en la planificación territorial.

\section{RESULTADOS Y DISCUSIÓN}

\section{$\underline{\text { Geomorfología }}$}

La subcuenca del Río Gil González está conformada por sistemas montañosos de origen estructural, con relieve predominante escarpado a muy escarpado. Presenta pendientes de suaves a moderadamente inclinadas y escarpadas. Se pueden distinguir tres tipos de relieves muy marcados, dominados por el tipo de roca y el grado de desgaste por intemperismo. Figura 1. 
Relieve Montañoso: Dominado por elevaciones entre 200 y $320 \mathrm{msnm}$. Las pendientes entre $25^{\circ}$ a $30^{\circ}$. Se distinguen los cerros Montaña San Cristóbal y La Virgen entre las mayores alturas. Colinas: Alcanza elevaciones medias de hasta $175 \mathrm{~m}$. Pueden apreciarse mesetas, relieve plano con elevación entre 150 hasta $200 \mathrm{~m}$. Las pendientes tienen un rango entre $15^{\circ}$ y $25^{\circ}$, son suaves a moderadamente escarpadas.

Valles: El río Gil González corre sobre un valle de considerable extensión, que puede alcanzar más de un kilómetro de ancho. El

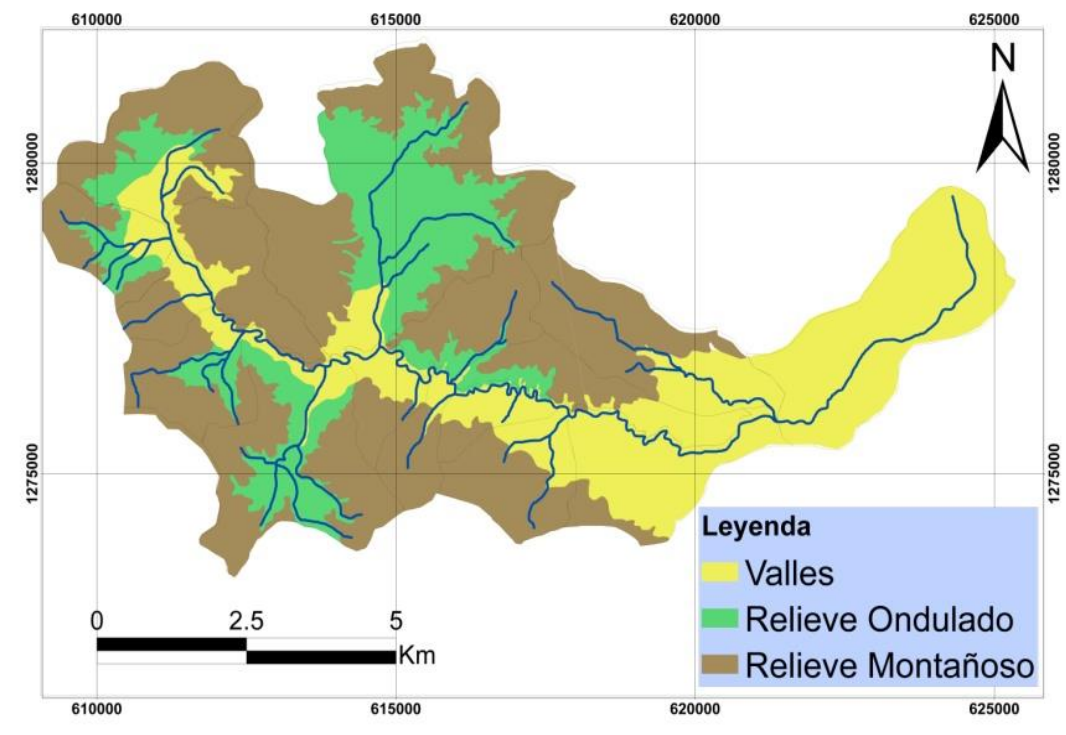

Figura 1. Relieve Gil González. y el ensanchamiento de las zonas de inundación. Están formados por sedimentos arrastrados por las corrientes. Las pendientes oscilan entre $0^{\circ}$ a $10^{\circ}$.

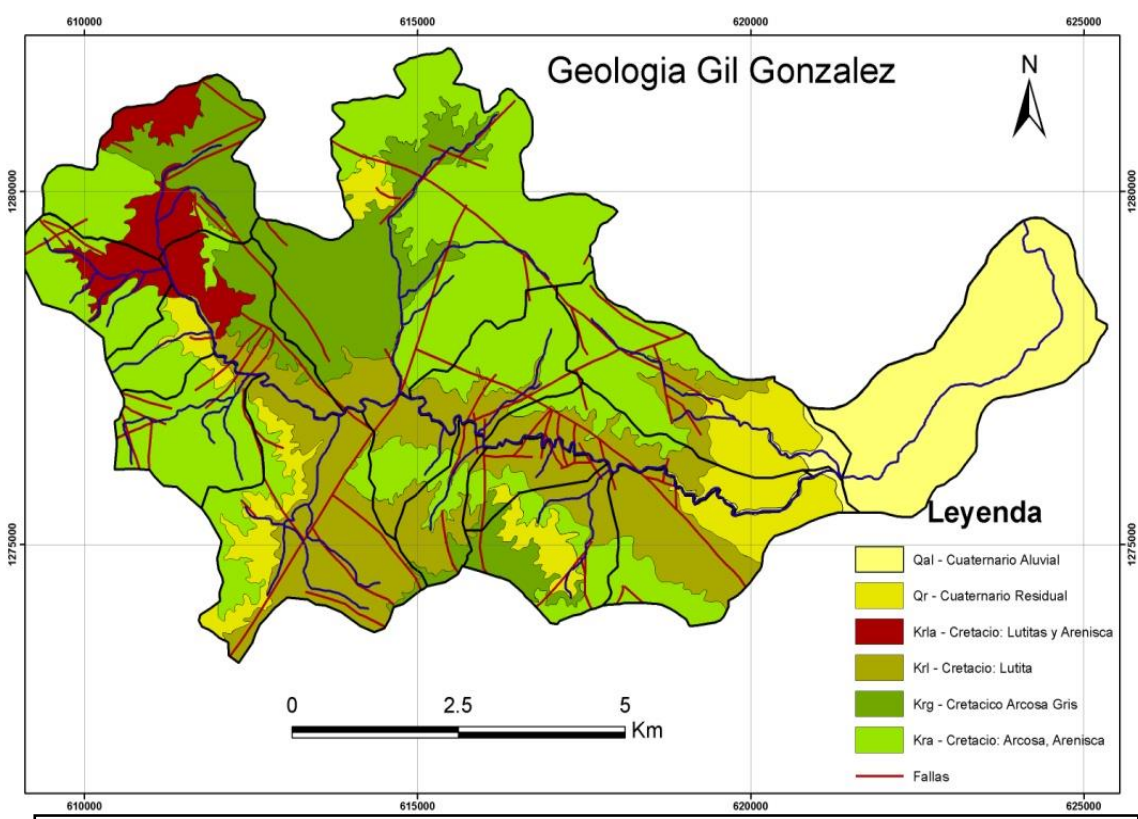

Figura 2. Geología Gil González.

\section{$\underline{\text { Geología }}$}

La subcuenca Rio Gil

González está constituida por sedimentos cretácicos agrupados en la Formación Rivas y Sedimentos Cuaternarios producto de la erosión. Se definieron 6 unidades litológicas: Arcosas (As), en el área de Mata de Caña, Santa Berta y San Pedro las Mesas, Areniscas de Grano Grueso (GG), en las áreas el Guacalito y Santa Berta; Lutitas (Lt), principalmente en San Juan Viejo, La Gloria y San Pedro; Arenisca y Lutitas (AL), cerca de Santa Berta y La Cantimplora. Las unidades están afectadas por sistemas de fallas y 
fracturas, con dirección predominante NW-SE y NE-SW, con ángulos de $120^{\circ}$ entre sí. El espaciamiento entre los grupos de fracturas es de alrededor de $10 \mathrm{~cm}$., ocasionalmente, denso 1-2 $\mathrm{cm}$. La longitud oscila entre $1 \mathrm{a} 5 \mathrm{~m}$. Con menor frecuencia ocurren grupos de fracturas que forman ángulos de $18^{0}$ a $29^{\circ}$, con las principales.

Los materiales geológicos más recientes son representados por: Unidad Cuaternario Residual (Qr) formada por productos de la meteorización, directo sobre las rocas de la unidad As. Unidad Cuaternario Aluvial (Qal), cubren la parte baja de la subcuenca, la mayoría de los cauces de los ríos y quebradas y las aéreas más próximas al Lago Cocibolca.

\section{$\underline{\text { Tipos y uso de suelos }}$}

La mayor parte de la subcuenca del Río Gil González está cubierta por suelos arcillosos clasificados como Alfisoles: Series San Rafael y Rivas, suelos Vertisoles y suelos Entisoles o aluviales. Los suelos Alfisoles ocupan la mayor parte de la subcuenca del Río Gil González, desarrollándose en las microcuencas de la parte alta y media pueden distinguirse en la parte alta y media del Río San Pedro-Las Mesas y Las Cañas al NE de la subcuenca (Rodríguez et al, 2003). Los Suelos Vertisoles Consisten de arcillas negras y pesadas; son profundos y moderadamente profundos, pobremente drenados.

En Mata de Caña los suelos son utilizados para el cultivo de arroz y ganadería. En San Juan Viejo y las Mesas se desarrolla la ganadería, se cultiva plátano y no tradicionales. En la parte baja, los suelos están siendo aprovechados para el monocultivo de caña de azúcar y para ganadería extensiva. Se están haciendo algunos esfuerzos de reforestación.

\section{$\underline{\text { Hidrogeología }}$}

La dirección preferencial del flujo de aguas subterráneas es SW-NE, con descarga regional en el Lago Cocibolca. Se distinguen cuatro acuíferos de importancia en la zona de estudio; tres descargan a la Laguna de Nocarime y

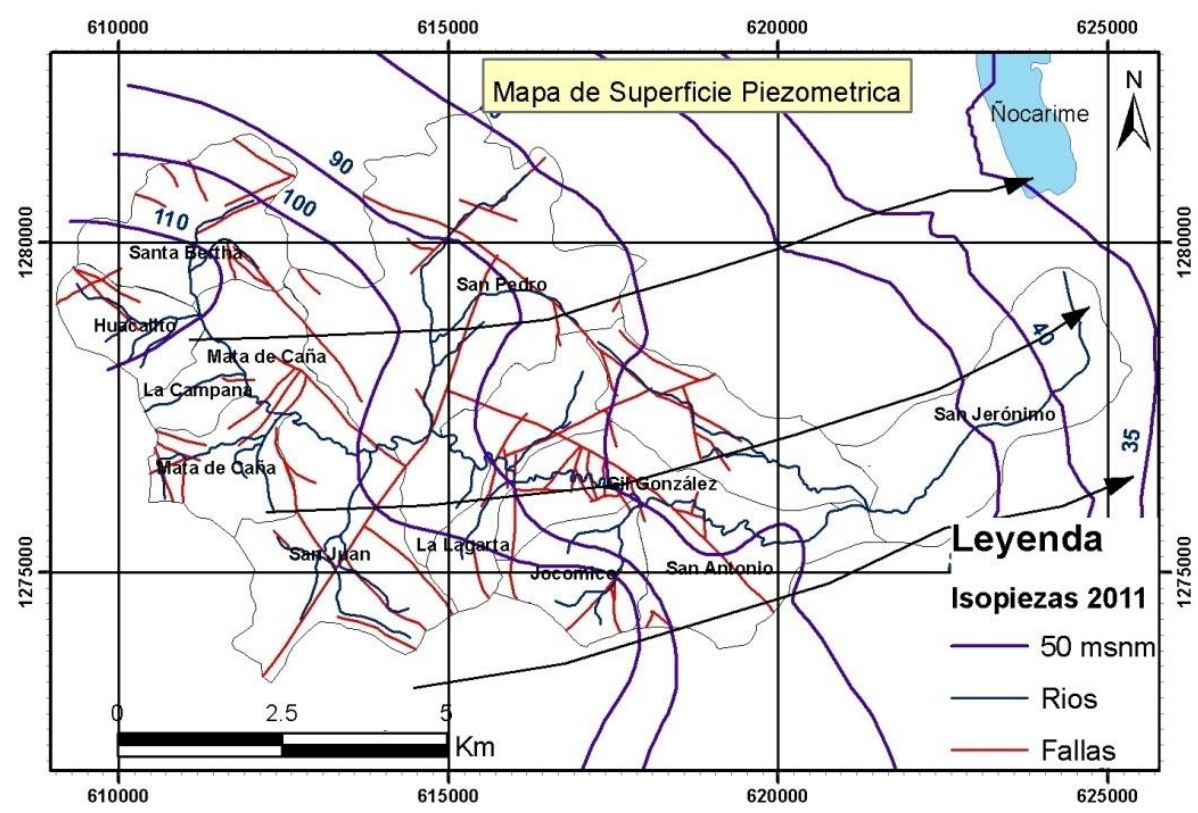

Figura 3. Superficie Piezometrica Gil González. 
posteriormente al lago y el otro es una importante zona donde la descarga de aguas subterránea mantiene un sistema de humedales. Los límites de los acuíferos están entre la Formación Rivas (que representa el basamento impermeable) y el Lago Cocibolca. Localmente se observa descarga de aguas subterráneas al rio Gil González y sus principales tributarios. La divisoria regional es a la altura de San Antonio, donde el anticlinal de Rivas dirige el flujo directamente al rio. Las estructuras de fallas crean tramos de gradiente, indicando esta estructura una zona importante de recarga local del acuífero.

El acuífero más productivo es el acuífero aluvial, en la parte baja de los ríos y las planicies de Rivas, debido a que presenta mayor extensión y una zona de recarga amplia, sobre todo por recarga por excedente de riego.

\section{Zonificación hidrogeológica}

A partir de los datos obtenidos se delimitaron zonas con similitud hidrogeología, se establecieron cuatros sistemas acuíferos. Esto permite establecer zonas geográficas de similares características hidrogeológicas. Esto define el comportamiento en cuanto a recarga, geología, tipo de suelos y parámetros hidráulicos.

Las zonas definidas presentan características marcadas; los acuíferos fracturados cubren una extensa área del acuífero, donde se ubica la mayor parte de la población y donde se realizan actividades agropecuarias extensivas, sin embargo presentan transmisividades muy baja los reduce la capacidad del acuífero si este es sometido estrés por extracciones tanto del rio, donde mayormente descarga el acuífero como por pozos o norias. Los acuíferos intramontanos son los de menor extensión y debido a sus características geológicas también presenta permeabilidades muy bajas, sin embargo es un área con poca población y mayormente es utilizada para aéreas de reforestación. En el caso de los acuíferos aluviales cubren la mayor parte del área de estudio, generalmente se ubican en las partes más bajas donde las deposición de materiales geológicos con alta porosidad y capacidad de transmitir agua, así mismo dentro de esta zona se realizan las actividades agropecuarias más intensas, cultivo de caña de azúcar, musáceas y frutales, grandes extensiones de áreas de pastoreo, es por estas actividades sumado a las características propias del acuífero que le confiere una mayor vulnerabilidad en cuanto a contaminación por plaguicidas, nitratos, salinización de suelos, reducción del caudal de los ríos por extracción, disminución de los niveles de aguas subterráneas por bombeo. 


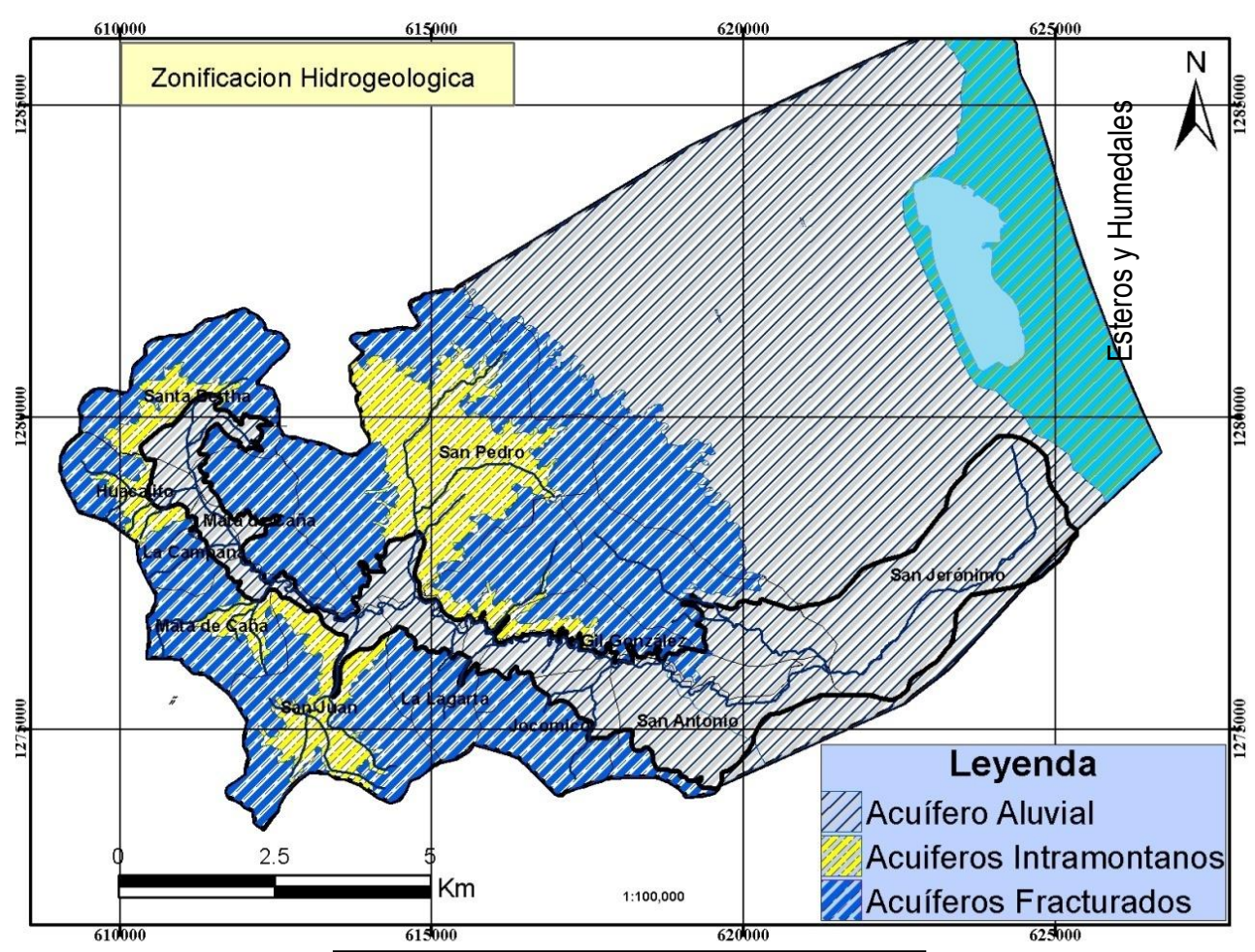

Figura 4. Zonificación Hidrogeológica.

\section{CONCLUSIONES.}

A partir de los datos obtenidos se delimitaron zonas con similitud hidrogeología, se establecieron cuatros sistemas acuíferos (Fig. 2), esto permite establecer zonas geográficas caracterizadas por presentar similares características hidrogeológicas, las que les permiten comportarse de igual manera en cuanto a recarga, geología, tipo de suelos y parámetros hidráulicos al momento de transmitir agua.

Las zonas definidas presentan características que permite diferenciarlas desde el punto de vista hidrogeológico, así como por las diferentes actividades que se realizan dentro de ellas; los acuíferos fracturados cubren una extensa área, son de baja permeabilidad y los más poblados aumentando la vulnerabilidad frente a la explotación de aguas, los acuíferos intramontanos son de baja permeabilidad pero con poca población y mayor zonas de bosques, los acuíferos aluviales son más permeables y donde se realizan las actividades más intensa de cultivo, siendo más vulnerables a contaminación por plaguicidas.

La zonificación hidrogeológica de la subcuenca Río Gil González sirve como una herramienta para planificar el uso y manejo sostenible de la cuenca y la ejecución de programas y proyectos 
específicos dirigidos a conservar, preservar, proteger o prevenir el deterioro y/o restaurar la cuenca hidrográfica.

\section{RECOMENDACIONES}

Establecer una red de monitoreo de la calidad de aguas superficiales y subterráneas dentro de la subcuenca Rio Gil González y el Acuífero Belén, incluyendo la instalación de una regla limnimétrica en la parte baja cerca de la desembocadura del rio Gil González, que permita poder establecer el monitoreo de caudales y construir la curva de gasto.

Realizar un censo de uso y consumo de agua que sea realista y en el que refleje con la mayor precisión posible cuanto es realmente lo que cada usuario de agua realmente consume, con fin de mejorara el balance de aguas y permitir establecer la dotación de cada habitante tanto en uso para consumo humano, uso domestico y uso para fines agrícolas que permita un mejor manejo de los recursos hídricos.

\section{BIBLIOGRAFÍA}

Custodio. E y Llamas. M.R. Hidrología Subterránea. 2da. Edición. Universidad de Barcelona, 2001.

Krasny J. 1995. Mapa hidrogeológico de la zona del Pacífico de Nicaragua. INETER-GTZ. Reporte Interno.

Krásný, J. and Hecht, G. Estudios Hidrogeológicos e Hidroquímicos de la Región del Pacífico de Nicaragua. INETER, 1998 